\title{
Educational Background Qualifications of MBA Students of Usmanu Danfodiyo University, Sokoto (UDUS) and Their Performance in the MBA Examinations: A Relationship Study
}

\author{
Amina Abdullahi \\ Muhammad Sani Umar \\ Department of Business Administration, \\ Faculty of Management Sciences, \\ Usmanu Danfodiyo University, Sokoto-Nigeria
}

\section{Doi:10.5901/jesr.2013.v3n8p99}

\begin{abstract}
The study examines the relationship between background educational qualifications of students and their performance in the MBA examinations. It uses student's entry qualification into the MBA programme at UDUS and their performance in the MBA examinations. The population of the study comprises of 212 graduates of MBA programme for four academic sessions which were randomly selected and withheld for confidentiality of the students' results. A sample of 117 MBA students was selected for satisfying the requirements of the study. Student record (file) and senate approved results served as the main sources of data collection. The data collected were analysed using frequency table, percentage and average. The study finds that there is a significant relationship between student's background educational qualification and his/her performance in the MBA programme. The study also finds that entry qualifications need not be in business or related areas for a student to perform better in the MBA examinations. This study therefore recommends among others that Business Schools should continue with the practice of obtaining postgraduate diploma in management or related areas if background educational qualification of the candidate is not in business or related areas before securing admission into the MBA programme.
\end{abstract}

Keywords: Background educational qualification, Performance, MBA programme, MBA examinations, Usmanu Danfodiyo University, Sokoto (UDUS)

\section{Introduction}

Universities are critical players in the national transformation agenda of Nigeria's President, Dr. Goodluck Jonathan. This may be the reason why National Universities Commission (NUC) is increasingly subjecting Nigerian universities to performance inspection. Zezekwa and Mudavanhu (2011) opine that part of the success of the educational process is measured in the quality of students' academic performance still at university. According to them differences in entry qualifications for a particular university course may be strong predictors of students' educational attainment. Thus, the more an individual is educationally exposed the easier things becomes for him or her. The brain opens up and the understanding of issues flow naturally. The previous knowledge gained while climbing the educational ladder will pave the way for good performance at that level and other higher levels.

According to Schneider (n.d.) education is theorised to have an influence on individuals' attitudes by facilitating the evaluation of complex social situations, widening the individual's knowledge and horizon of experiences as well as by direct exposure to norms and values in 
educational institutions.

Many factors determine the performance of students. These include teacher's academic qualification (Adeyemi, 2012); entry qualification (Cheesman, Simpson, and Wint, 2006); gender disparity (Figueroa, 2000); financial constraints (Bailey, 2002) etc.

The educational qualification of MBA student and his/her performance largely depends greatly to his/her learning behaviour. The idea of previous experience in relation to learning situation is of enormous importance in achieving high result. Learner's history of experience shows a varying degree of opportunity to learn. Consequently, each learner is different in his/her overall acquired ability to learn (Charles, 1978).

Thus, to a great extent, student's past experience of knowledge help him/her a lot in performing and achieving better in another learning situation. However, Bloom and Carrot (1968) argue that with respect to previous experience, aptitude or ability to perform better is best considered a function of the opportunity to learn (time spent attending to the task, and quality of the instruction). Their assumption is that, if the quality of the institution is optimal for each learner, and if each learner attends for the amount of time necessary for him/her to master the task, then performance will not be normally distributed among the learners.

Over the years, the Postgraduate School of UDUS has been admitting candidates with different educational qualifications (Arts, Sciences, etc) into Masters Degree in Business Administration (MBA) full time programme. The entry qualifications of these students range from those with required first degree to those whose entry qualifications are not related to business or other related areas and have to enroll into the programme with Postgraduate Diploma in Management or Business Administration (PGDM or PGDBA) to meet one of the requirements for the MBA programme.

It is in this context that the research attempts to examine the relationship between the performance of MBA students and their entry educational qualifications. In an attempt to investigate this problem, the study is divided into four sections. Section two discuses the research methodology, section three presents and analysis the data collected while the last section concludes the paper.

\section{Research Methodology}

This study is a longitudinal research design. It uses the student entry qualification into the MBA programme at UDUS and their performance in the MBA examinations. The data collected was used to examine whether if there is a significant relationship between background educational qualifications of MBA students and their performance in MBA examinations.

The population of the study comprises of 212 graduates of MBA programme of UDUS for four academic sessions. The years were randomly selected and withheld for confidentiality of the students' results but they are coded as W, X, Y and Z academic sessions.

The whole candidates for the four academic sessions were included in the study except those that deferred their admission for the session under consideration or senate did not their results due to one problem or the other. All the students use for the research and those with different problems are grouped/categorized in the Table 1.

Table 1: Category Of Students Who Participated In The Research

\begin{tabular}{|c|c|c|c|c|c|c|c|c|c|c|c|c|c|c|c|c|c|}
\hline $\begin{array}{c}\text { Categories of } \\
\text { student } \\
\text { Background } \\
\text { educational } \\
\text { qualification }\end{array}$ & \multicolumn{4}{|c|}{$\begin{array}{l}\text { Students With entry } \\
\text { qualification.and } \\
\text { performance }\end{array}$} & \multicolumn{4}{|c|}{$\begin{array}{c}\text { students with } \\
\text { performance only }\end{array}$} & \multicolumn{4}{|c|}{$\begin{array}{l}\text { Students with } \\
\text { deferred } \\
\text { results }\end{array}$} & \multicolumn{4}{|c|}{$\begin{array}{l}\text { Students who } \\
\text { deferred their } \\
\text { admission }\end{array}$} & \multirow[t]{2}{*}{$\begin{array}{l}\text { Grand } \\
\text { Total }\end{array}$} \\
\hline & W & $X$ & $Y$ & $Z$ & W & $x$ & $Y$ & Z & W & $X$ & $\mid Y$ & Z & W & $X$ & $Y$ & & \\
\hline
\end{tabular}




\begin{tabular}{|c|c|c|c|c|c|c|c|c|c|c|c|c|c|c|c|c|c|}
\hline B.SC;B.A R.A & 13 & 16 & 25 & 30 & & & & & - & 01 & - & 07 & - & 01 & 01 & 01 & \\
\hline $\begin{array}{c}\text { B.SC;N.B.A + } \\
\text { PGDM }\end{array}$ & 06 & 04 & 07 & 05 & & & & & - & - & - & 02 & - & - & - & 01 & \\
\hline $\begin{array}{c}\text { HND; BA R.A } \\
+ \\
\text { PGDM }\end{array}$ & 03 & 06 & 08 & - & & & & & - & - & - & - & - & - & - & - & \\
\hline $\begin{array}{c}\text { HND; N.B.A + } \\
\text { PGDM }\end{array}$ & - & - & 01 & 01 & & & & & - & - & - & - & - & - & - & - & \\
\hline $\begin{array}{c}\text { HND ; B.A. } \\
\text { R.A + PGDM }\end{array}$ & 12 & 15 & 07 & 05 & & & & 01 & - & - & 01 & 01 & - & 01 & - & \\
\hline $\begin{array}{c}\text { HND; N.B.A + } \\
\text { PGDM }\end{array}$ & 02 & 04 & 01 & - & & & & - & - & - & - & - & 01 & - & - & \\
\hline SUB TOTAL & 36 & 45 & 49 & 41 & 15 & 03 & 04 & - & 01 & 01 & - & 01 & 01 & 02 & 02 & 02 & \\
\hline
\end{tabular}

Source: Field survey

Table 1 shows that students under the category (students with qualification and performance) with a total of 171 were the ones selected to participate in this study because of availability of their files and results. The remaining students were not selected because of one problem or the other as shown in Table 1. Those with only examinations results but without files numbered 22; those that had deferred results were 12. Lastly, 7 students deferred their admissions in the four years under review.

The data collected from students' records were grouped into two categories i.e. entry background educational qualifications of the students (Student file) and their performances in the MBA examinations (Senate approved MBA results) for the four sessions. These were analysed using frequency table, percentage and average.

For clarity and lucid presentation of the data, the information collected from the students' record (files) were grouped into six sets of categories i.e: (a) B.Sc Business Administration and related areas coded as B.Sc. B.A R.A (b) B.Sc Non Business Areas plus PGDM, coded as B.Sc N.B.A + PGDM (c) HND Business Administration and Related areas plus PGDM, coded as HND B.A.R.A + PGDM (d) HND Non Business areas plus PGDM coded as HND NBA + PGDM (e) HND Business Administration and related Areas plus PGDM, coded as HND B.A.R.A + PGDM (f) HND Non Business areas plus PGDM coded as HND N.B.A. + PGDM.

Again, the second category of data collected was the Senate approved results which was also grouped into three. They are (a) Quantitative performance: coded as QP used where applicable (b) Theoretical performance, coded as TP, used where applicable, (c) General performance, coded as GP used where applicable in the research.

Note also that PGDM used in this research represents other postgraduate diplomas (PGD) that qualified candidates into the MBA programme i.e PGD Accounting, PGD Bus. Admin., PGD marketing and other related fields/areas. AV is also used in the research for Averages, and where applicable.

\section{Results}

\subsection{Quantitative performance Analysis}

To examine the quantitative performances of the students for the four academic sessions, Table 2 shows their Average General Performances 
Table 2: Average quantitative performances for the four academic sessions

\begin{tabular}{|c|c|c|c|c|c|c|c|c|}
\hline $\begin{array}{r}\text { Acad. Yrs } \\
\text { Stud. Qual. Catego. }\end{array}$ & $W$ & $X$ & $Y$ & $Z$ & Total GPA & Average GPA & Percentage \% & Position \\
\hline B.Sc B.A.R.A & 2.16 & 2.98 & 3.12 & 3.02 & 11.28 & 2.82 & 56.40 & $4^{\text {TH }}$ \\
\hline B.Sc N.B.A + PDGM & 3.90 & 3.58 & 3.59 & 3.19 & 14.26 & 3.57 & 71.40 & $1^{\text {TT }}$ \\
\hline HD B.A.R.A + PDGM & 195 & 3.23 & 3.00 & - & 8.18 & 2.73 & 54.60 & $6^{\text {TH }}$ \\
\hline HD N.B.A+ PDGM & - & - & 4.00 & 1.50 & 5.50 & 2.75 & 55.00 & $5^{\text {TH }}$ \\
\hline HND B.ARA + PDGM & 3.29 & 3.13 & 3.00 & 1.97 & 11.59 & 2.85 & 57.00 & $3^{\text {RD }}$ \\
\hline HND N.B.A + PDGM & 2.57 & 3.35 & - & - & 5.96 & 2.98 & 59.60 & $2^{\mathrm{ND}}$ \\
\hline
\end{tabular}

Table 2 indicates that those with B.Sc, N.B.A + PGDM performed more better in all the four academic sessions with total GPA of 14.26 and AV. GPA of 3.57.

\subsection{Theoretical Performance Analysis}

This section examines all the theoretical courses of MBA both core and electives offered by the MBA programme including research project, to arrived at their theoretical performances.

Table 3: Average general performances of MBA students in theoretical courses for the four academic sessions.

\begin{tabular}{|c|c|c|c|c|c|c|c|c|}
\hline $\begin{array}{c}\text { Academic years } \\
\text { Stud. Qual. Categoreis }\end{array}$ & W & X & Y & Z & Total GPA & AV. GPA & Percent \% & Position \\
\hline B.Sc B.A.R.A & 3.02 & 3.27 & 3.30 & 3.29 & 12.88 & 3.22 & 64.40 & $2^{\text {ND }}$ \\
\hline B.Sc N.B.A + PGDM & 3.55 & 3.51 & 3.29 & 3.36 & 13.71 & 3.43 & 68.60 & $1^{\text {ST }}$ \\
\hline HD B.A.R.A + PGDM & 2.87 & 3.38 & 2.95 & - & 9.20 & 3.97 & 61.40 & $4^{\text {TH }}$ \\
\hline HD B.A.+ PGDM & - & 3.17 & 3.00 & 2.70 & 8.87 & 2.96 & 59.20 & $5^{\text {TH }}$ \\
\hline HND B.A.+ PGDM & 3.18 & 3.13 & 3.08 & 3.14 & 12.53 & 3.13 & 62.60 & $3^{\text {RD }}$ \\
\hline HND N.B.A.+ PGDM & 3.28 & 3.38 & 1.20 & & 7.83 & 2.61 & 52.20 & $6^{\text {TH }}$ \\
\hline
\end{tabular}

Source: Field Survey

Table 3 shows that MBA students with B.Sc, N.B.A + PGDM educational background performed more better at the over all level with total G.P.A of 13.71 and an AV. of $3.43(68.60 \%)$.

\subsection{General Performance Analysis}

This segment examines and analyzes both quantitative and theoretical performances of the students in the MBA programme. This is to investigate the extent to which performances in either quantitative or theoretical courses determine the students general performances in the MBA programme as shown in Table 4.

Table 4: Students' General Performances for the four academic sessions

\begin{tabular}{|c|c|c|c|c|c|c|c|c|c|c|c|c|}
\hline Years \& Perf & \multicolumn{3}{|c|}{ W } & \multicolumn{3}{|c|}{$x$} & \multicolumn{3}{|c|}{$Y$} & \multicolumn{3}{|c|}{ Z } \\
\hline Stud. Qual. & Q & $\mathrm{T}$ & G & Q & $\mathrm{T}$ & G & Q & $\mathrm{T}$ & G & Q & $\mathrm{T}$ & G \\
\hline B.SC B.A.R.A & 2.16 & 3.02 & 2.85 & 2.85 & 3.17 & 3.22 & 3.12 & 3.30 & 3.03 & 3.02 & 3.29 & 3.42 \\
\hline
\end{tabular}




\begin{tabular}{|c|c|c|c|c|c|c|c|c|c|c|c|c|}
\hline B.SC. N.B.A + PGDM & 3.90 & 3.55 & 3.62 & 3.62 & 3.51 & 3.82 & 3.59 & 3.29 & 3.37 & 3.19 & 3.36 & 3.18 \\
\hline HD B.A.RA + PGDM & 1.95 & 2.87 & 2.69 & 3.23 & 3.38 & 3.44 & 3.00 & 2.95 & 2.99 & - & - & \\
\hline HD N.B.A + PGDM & - & - & - & - & - & - & 4.00 & 3.00 & 3.16 & 1.50 & 2.70 & 2.50 \\
\hline HND B.A.R.A + PGDM & 3.29 & 3.18 & 3.19 & 3.13 & 3.17 & 3.23 & 3.00 & 3.08 & 3.09 & 1.97 & 3.14 & 2.93 \\
\hline HND NB.A + PGDM & 2.57 & 3.25 & 3.25 & 3.39 & $3 . .38$ & 3.35 & 0.00 & 1.20 & 1.00 & - & - & \\
\hline
\end{tabular}

Source: Field Survey

Table 4 reveals that during academic sessions $W, X, Y$ and $Z$, the MBA students quantitative and theoretical performances to a great extent determine their general performances. In year $Y$, students with HND, NBA + PGDM had GPA of 4.00 as their quantitative performance and it was the highest score. This determined the category's general performance of 3.16. Again, this group of students scored 3.00 as their theoretical performance in the same year. For year W, the table reveals that those with B.Sc., N.B.A + PGDM scored GPA of 3.90 as quantitative performance while their theoretical performance stood at GPA of 3.55 representing a general performance of 3.62.

Table 4 also shows that the least quantitative performance $(0.00)$ was scored in year $Y$ by those with HND, N.B.A + PGDM while the least theoretical performance of 1.00 was scored by the same category of students in the same year. This result may explain the general allegation against polytechniques of providing poor quality of education.

This also applies to all the remaining group of students in the sense that, G.P. depends more or less on the level/score obtained in both quantitative and theoretical courses. Obviously, the performance of a student in any of the group of courses contributes to the overall performance of the students.

\subsection{Background Educational Qualification of MBA students and their performances in Final Examinations}

This segment investigates the performance of MBA students in the final examinations in relation to the student's background educational qualifications.

Table 5: Summary of MBA students overall GPA for the four academic sessions.

\begin{tabular}{|c|c|c|c|c|c|c|c|c|}
\hline $\begin{array}{c}\text { Academic years } \\
\text { Stud. Qualification Categoreis }\end{array}$ & W & X & Y & Z & Total GPA & AV. GPA & Percentage \% & Position \\
\hline B.Sc B.A.R.A & 2.85 & 2.22 & 3.03 & 3.42 & 12.52 & 3.13 & 62.60 & $2^{\text {TD }}$ \\
\hline B.SC N.B.A + PGDM & 3.62 & 3.52 & 3.37 & 3.18 & 13.69 & 3.41 & 68.40 & $1^{\text {ST }}$ \\
\hline HD B.A.R.A + PGDM & 2.69 & 3.44 & 2.99 & - & 9.12 & 3.04 & 60.80 & $4^{\text {TH }}$ \\
\hline HD B.A.+ PGDM & - & - & 3.16 & 2.50 & 5.66 & 2.83 & 56.60 & $5^{\text {TH }}$ \\
\hline HND B.A.+ PGDM & 3.19 & 3.23 & 3.09 & 2.93 & 12.44 & 3.11 & 62.20 & $3^{\text {RD }}$ \\
\hline HND N.B.A.+ PGDM & 3.25 & 3.35 & 1.00 & - & 7.60 & 2.53 & 50.60 & $6^{\text {TH }}$ \\
\hline
\end{tabular}

Source: Field Survey

Table 5 affirms that there is a relationship between MBA students' background educational qualifications and their performances in final examinations in the sense that the average performances of the six categories of the MBA students differed. As seen in Table 5 , there exists a relationship between/among the level of GPAs and percentages obtained by each category of students i.e. holders of entry qualification B.Sc NBA + PGDM scored the highest GPA of 3.41 $(68.40 \%)$ while those with B.Sc B.A.R.A + PGDM scored GPA of $3.13(62.60 \%)$ and HND B.A.R.A + PGDM holders scored GPA of 3.11 (62.20\%). Again, those with HND B.A.R.A + PGDM scored GPA 
of $3.04(60.80 \%)$, HND, BA + PGDM obtained GPA of $2.83(56.60 \%)$. Finally, students with entry qualification HND NBA + PGDM scored GPA of 2.53 (50.60\%). These findings imply that those that have attained Bachelor degree (related or unrelated) as their entry qualification perform better than HND/HD holders (related or unrelated) in the MBA examinations.

\section{Conclusions}

The idea of previous experience in relation to learning situation is of enormous importance in achieving high result. To a great extent a student's past experience of knowledge helps him/her a lot in performing and achieving better in another learning situation. The study found that there is a significant relationship between student's background educational qualification and his/her performance in the MBA programme.

This study therefore recommends that Business Schools should continue with the practice of requiring MBA applicants to obtain postgraduate diploma in management or related areas if their background educational qualifications are not in business or related areas. There is also the need by supervisory agencies of polytechniques to ever more monitor the performance of teachers because quality improvement in tertiary education depends on the quality of instructions in the classroom.

\section{References}

Adeyemi, K.J. (2012). Effects of teacher's academic qualification on student's performance at the secondary school level. Retrieved from http://www.academia.edu/346972/Effect_of_teachers _academic_qualification_on_students_Performance_at_the_secondary_level

Cheesman, J; Simpson, N and Wint, A.G. 2006. Determinants of student performance at University: Reflections from the Caribbean.UWI.

Figuero,M.(2000). Making sense of male experience: The case of academic Underachievement in English Speaking Caribbean. IDS Bulletin 31 (2 MBA (UDUS) Handbook 2006.

Melvin, J.W. (1982): Education and Living Standard, Onlando, Brooks and Werner Inc. Franscisco: Freeman and Co.

Zezekwa, N. and Mudavanhu, Y. (2011). The Effects of entry qualifications on student's performance in University science courses: The case of Bindura University of science education. African J ournal of Education and Technology, Volume 1 Number 3, pp. 32-39 http://sachajournals.com/documents /BINDURA002.pdf

Schneider S. (n.d.). Measuring Educational Attainment. Leibniz Institute for the Social Sciences (GESIS)). Retrieved from http://www.surveynet.ac.uk/sqb/topics/education/sqb_education_schneider.pdf 